\title{
Differentiation AND Cost Leadership \\ Strategies: A Strategic Continuum \\ of Alternatives
}

\author{
Ronald F. Green \\ East Tennessee State University \\ Johnson City, Tennessee \\ James P. Jolly \\ Idaho State University \\ Pocatello, Idaho \\ Alok Srivastava \\ Georgia State University \\ Atlanta, Georgia
}

Quite prominent in recent strategic management literature is the attempt of researchers to explain successful business-level performance in terms of strategic group membership. Of the many models attempting to describe strategic groupings, two have dominated. Miles and Snow [7] developed a four strategy typology calling for classification of firms as either defenders, prospectors, analyzers, or reactors. Classification depends upon the firm's perspectives on dealing with the basic problems referred to as the entrepreneurial, engineering, and administrative problems. Defenders and prospectors represent opposing views on approaches to dealing with these problems, while analyzers represent firms following mid-ranged alternatives. Reactors are strategic failures, characterized as reacting to environmental conditions rather following a consistent strategic plan. Michael Porter's [11] three dimension typology has also received much attention as an explanation of strategic groupings. Porter emphasized that firms can best be described in terms of three generic strategies that explain how a firm can cope with the competitive forces of the marketplace. Porter labeled these strategies as cost leadership, differentiation, and focus.

Cost leadership firms emphasize managetial attention to cost control with a general theme of outperforming competitors through efficiency rather than product quality or service. Firms following such a strategy are better prepared to withstand pressures when prices are driven down by the forces of the marketplace. A differentiated firm attempts to create a real or perceived difference in its product or service, with the objective of establishing an industry wide customer base that views its product or service as being superior to that of competitors. Ideally, differentiation will occur in several dimensions such as superior quality products, service, delivery, etc. The main benefit derived from such a strategy is that brand loyalty reduces price sensitivity and results in higher margins. While not insulating the firm from cost concerns, they are of secondary importance. It is important to note, however, that even through

Journal of Business Strategies, Volume 7, Number 1 (Spring 1990) 
buyers throughout the industry may acknowledge the differentiated firm's superiority they may not be able or willing to pay the higher prices that often result. The focus strategy may take several forms, but is based upon the firm's ability to identify a particular buyer group, segment of the product line, or geographic market upon which it can focus its attention. By narrowing its marketing target, the firm hopes to better meet the needs of its consumer base, resulting in either differentiation from better services or cost leadership through marketing efficiencies.

Porter also addressed the issue of those firms who fail to develop strategy consistent with at least one of his generic strategies by labeling such firms as "stuck in the middle." Such firms are doomed to low market share and low profitability because of failure to attract high-volume customers who demand low prices or high-margin customers associated with the differentiation strategy. Porter also issued the disclaimer that these relationships might not hold true for every situation. Certain industries preclude focus or differentiation strategies because of price competition resulting from the nature of the product sold. In addition, some firms within an industry might be able to achieve differentiation or focus without losing their low-cost positions. Porter's admission of these rare typology limitations is consistent with Miles and Snow's [7] view that typologies are not all encompassing and should be judged primarily on the existence of codification and prediction characteristics. Porter's typology has generated considerable interest as researchers have critically examined his theory from a variety of perspectives.

Dess and Davis [1] utilized multivariate techniques to study firms from the paint industry, finding evidence of differentiation and cost leadership strategies, but reporting mixed support for the focus strategy. Karnani [6] argued that the focus strategy is simply a combination of the other two generic strategies. Karnani also argued, along with others [10], that the two remaining strategies, differentiation and cost leadership, are independent, enabling a firm to follow both with equal intensity. While Porter recognized this possibility, he maintained that they are mutually exclusive for the vast majority of firms. Parks' [9] 1985 study found support for Porter's claim, concluding that firms tend to pursue either strategy, but seldom both. Murray's [8] more recent study linking generic strategies to external preconditions has given rise to a contingency view that support the non-exclusivity position. This study is indicative of a stream of research ([2], [5]) which supports the existence of viable strategic alternative combinations available to most firms.

The mixed findings of those attempting to examine Porter's typology supports Porter's admission of typology limitations, with two areas of concern dominating the literature. The first deals with Porter's contention that successful firms follow strategies that can be identified and typed by three broad generic categories. Specifically, can the majority of firms be accurately labeled according to the typology and does strategic group membership correlate with success? The second concern deals with the mutual exclusivity of differentiation and cost leadership strategies. Do successful firms follow one primary generic strategy as Porter contends, or might success be 
achieved by firms that attempt to follow mixed strategies? A third concern dealing with the legitimacy of focus as a separate generic strategy has apparently been resolved by Porter's [12] more recent reference to the focus strategy as a means of obtaining a differentiated or low cost position within a market. His use of the terms focus/differentiated and focus/cost leadership lends to this interpretation.

\section{Methodology}

This research addresses these concerns by examining the typology's usefulness within the industrial marketplace. Hambrick and Lei's [4] study of contingency variables found the firm's user segment (consumer versus industrial) to be the most important contingency variable when examining a firm's strategic orientation. These findings, along with the lack of strategy research for the industrial marketplace, influenced the focus of this article.

With regard to previous research, Porter's use of discrete rather than continuous measures of a firm's strategic orientation is of particular concern. Limiting the focus strategy's role to one of market selection rather than strategic orientation, is it appropriate to describe a firm's strategic orientation in terms of a continuum anchored by firm's following pure differentiation or cost leadership strategies? It may be concluded that if Porter's contention were true, the majority of all successful firms would cluster to the extremes of the continuum, provided that a continuous measure of strategy is developed. The closer a firm's position to the mid-point of the continuum, the father away would the firm be clearly emphasizing a single generic strategy, a clear requirement for success according to Porter.

Figure 1 illustrates the hypothesized distribution of successful firms along the differentiation/cost leadership continuum. Should a continuous measure of strategy yield a significant number of successful firms ranging throughout the continuum, the interpretation follows that the mutual exclusivity of the differentiation and cost leadership orientation would be seriously challenged.

\section{Sample and Measurement}

A number of top executives of firms producing and selling industrial equipment and machinery were selected to participate in this study. This sample was felt to be representative of firms following a wide variety of strategic alternatives compatible with both differentiation and cost leadership strategies.

To capture information concerning both strategic orientation and performance, a self-report instrument was developed and distributed. The work of Dess and Davis [1] influenced the portion of the instrument used to collect information on intended business-level strategy. Respondents were asked to rate on a scale of 1 (not important) to 5 (very important) the importance of 21 competitive methods. Dess and Davis factor-analyzed these scales and compared respondents' perceived importance of competitive methods to those of a panel of experts. While the findings were inconclusive, the instrument and the panel's perspective on the importance of the competitive 


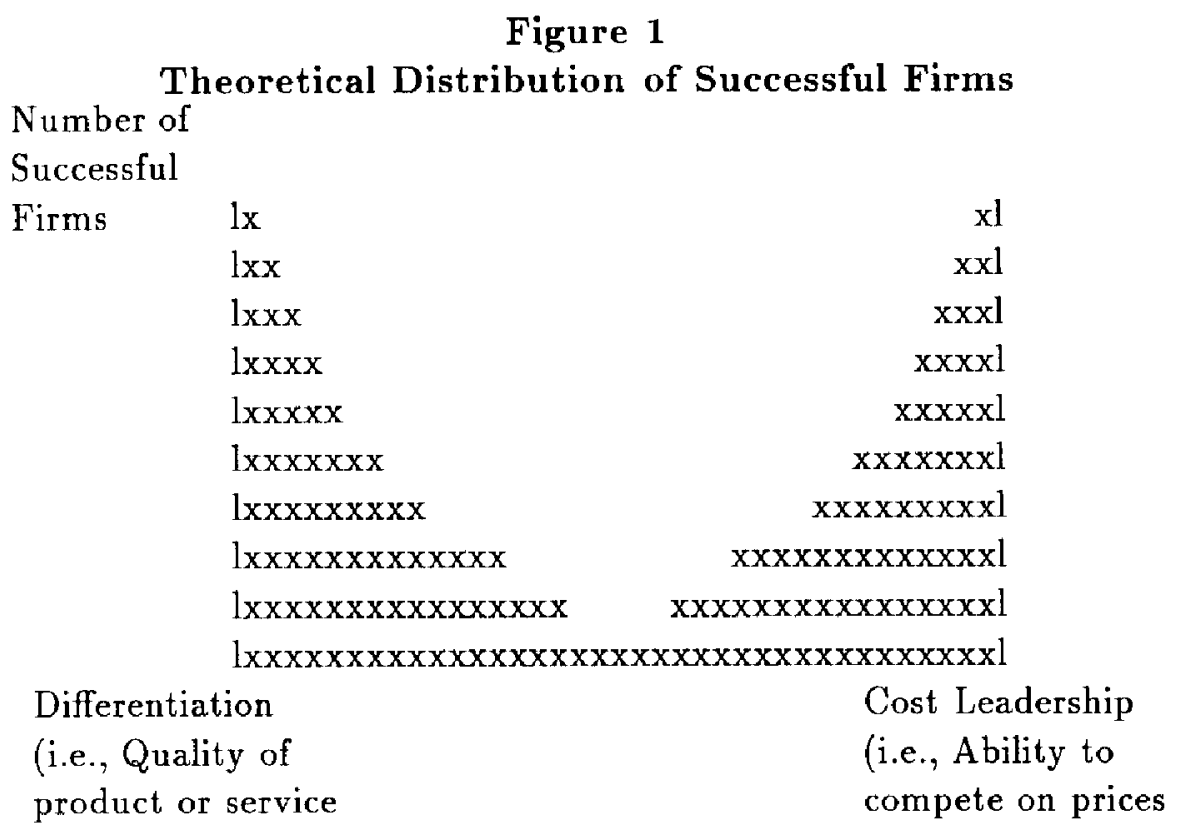

methods to Porters' generic strategies (See Table 1) led to the development of a continuous measure of strategic orientation for use in this study.

In the present study, index scores were calculated for each respondent for both differentiation and cost leadership strategies. The raw scores of the respondents' perceptions of competitive method importance to their firms' strategies were used as input. The differentiation index $(D)$ was calculated by summing the raw scores for the competitive methods (items 1, 10,11 and 18) considered most important to a differentiation strategy by the panel of experts from Dess and Davis. A similar procedure was used (including items 3, 7, 13, and 21) to calculate a cost leadership index $(C L)$ for each respondent. Finally, the differentiation index was subtracted from the cost leadership index, resulting in an overall strategy index $(S)$. The four positive inputs to the differentiation index would result in a purely differentiated firm theoretically scoring a five for each each of the inputs, resulting in a $D$ score of 20 . A firm that perceives some of the competitive methods as being of less importance than 5 would be less differentiated, according to the panel, and would have the $D$ score reduced accordingly. A similar rationale was used for the cost leadership index. The interpretation of the overall strategy index is that a firm following a pure strategy of either differentiation or cost leadership would achieve a $S$ score of positive or negative 16 , respectively. The closer the score to zero, the stronger the resemblance to a mixed strategy.

Finally, as an indicator of performance, the instrument required the respondent to indicate the firm's pre-tax return on investment (ROI) for the last fiscal year. The respondent was asked to check an appropriate block, with alternatives ranging 
Table 1

Experts' Views on Competitive Models

\begin{tabular}{rlccc} 
& & \multicolumn{3}{c}{ Experts } \\
\cline { 2 - 5 } & Competitive Method & $D$ & $C L$ & $F$ \\
\hline 1 & New Product Development & Most & $*$ & $*$ \\
2 & Customer Service & $*$ & Least & $*$ \\
3 & Operating Efficiency & $*$ & Most & $*$ \\
4 & Product Quality Control & $*$ & $*$ & $*$ \\
5 & Experienced/Trained Personnel & $*$ & $*$ & $*$ \\
6 & Maintain High Inventory Levels & $*$ & $*$ & Least \\
7 & Competitive Pricing & Least & Most & $*$ \\
8 & Broad Range of Products & Least & $*$ & Least \\
9 & Developing/Refining Exiting Products & $*$ & $*$ & $*$ \\
10 & Brand Identification & Most & $*$ & Most \\
11 & Innovation in Marketing & & & \\
& Techniques and Methods & Most & Least & $*$ \\
12 & Control of Channels of Distribution & $*$ & $*$ & $*$ \\
13 & Procurement of Raw Materials & Least & Most & Least \\
14 & Minimizing Use of Outside Financing & Least & $*$ & Least \\
15 & Serving Special Geographic Markets & $*$ & Least & Most \\
16 & Capability to Manufacture Special Products & $*$ & Least & Most \\
17 & Products in High Price Market Segments & $*$ & Least & $*$ \\
18 & Advertising & Most & $*$ & $*$ \\
19 & Reputation within Industry & $*$ & $*$ & $*$ \\
20 & Forecasting Market Growth & $*$ & $*$ & $*$ \\
21 & Innovation in Manufacturing Processes & $*$ & Most & $*$ \\
\hline & & & & \\
& & & & $*$
\end{tabular}

from "less than $0 \% "$ to " $15 \%$ and over" with a separate block for every three percent increment.

\section{Results}

The mail survey generated a total of 47 usable responses from executives representing a variety of industrial product firms primarily engaged in the manufacture and sales of equipment and machinery. It was determined from the responses that the sampled firms provided services to a variety of industries and experienced a considerable degree of price competition within their respective markets. The sampled firms were relatively small, reporting a mean total sales of $\$ 23.84$ million for the last fiscal year. Due to the ordinal nature of the scale used to measure performance, determination of actual profitability is difficult. A reasonable interpretation of the reported mean raw score of 4.30 would result in a mean pre-tax return of investment (ROI) for the last fiscal year of 8.4 percent. 
Of the 47 respondents, 11 reported the last fiscal year's ROI to be under three percent. These firms were classified for the purpose of this research as "Low Performance" firms. Those firms reporting ROI's ranging from three to 11.99 percent $(n=20)$ were classified as "Medium Performance" firms. This approximated the group of firms reporting profitability within one standard deviation of the mean. Those firms reporting ROIs above 12 percent $(n=16)$ were classified as "High Performance" firms.

Figure 2 presents a scatterplot with the horizontal axis depicting the strategy score $(S)$ and the vertical axis representing the raw performance score for all data points. The plotted number represents the number of observations at that space of the plot. Note the wide distribution of firms along the strategy continuum for all performance levels. The only notable exception is the cluster of performance level one firms (negative ROI for the last fiscal year) that is centered around the zero position on the strategy continuum. Also note that the $S$ scores ranged from -8 to 8 , while the maximum range was identified as -16 to 16 . The absence of firms on the theoretical extreme points on the continuum can be attributed to the nature of the scoring system. A firm that follows a pure generic strategy would not necessarily feel all other competitive methods to be of no importance. Rather, these competitive methods might be scored a somewhat neutral value of 3 on the 1 to 5 scale, resulting in a more realistic range of -8 to 8 .

\section{Figure 2}

Scatterplot of Performance by Strategy Score

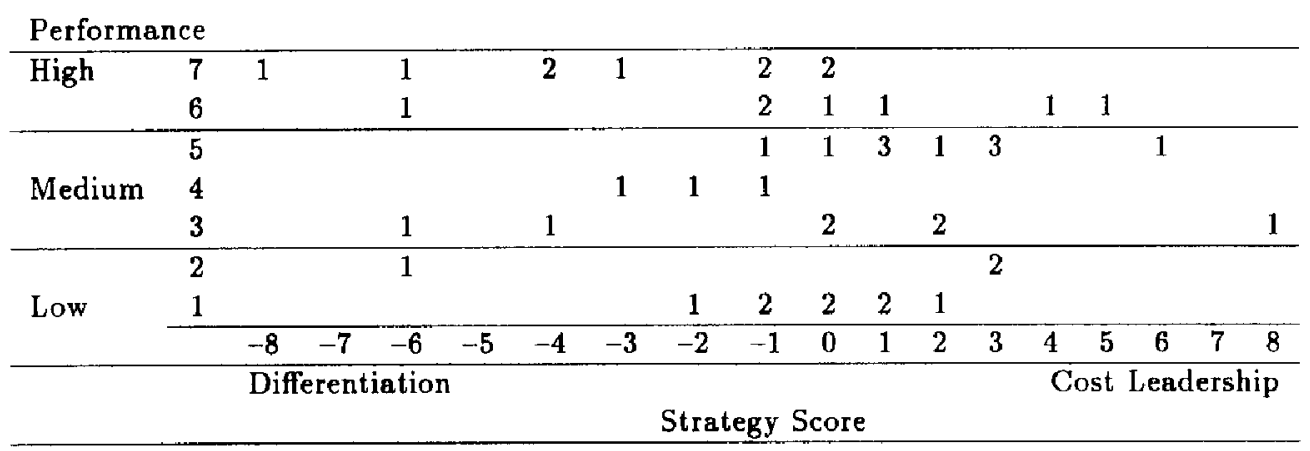

Figure 3 displays a bar-chart reflecting the distribution of the High Performance group firms throughout the strategy score continuum. This figure should be compared to the theoretical distribution (based on Porter) illustrated by Figure 1. Note the lack of support for the existence of the U-shaped curve.

Table 2 presents a cross-tabulation of performance and strategy. The sampled firms were found to have a mean strategy score of -.21 with a standard deviation of 3.28. Firms with an $S$ score within one standard deviation of the mean were deemed to be following a mixed strategy and were classified as such. Firms with an $S$ score greater than one standard deviation from the mean were classified as differentiated or cost leadership, dependent upon the direction of the variation. 
Figure 3

Actual Distribution of Successful Firms

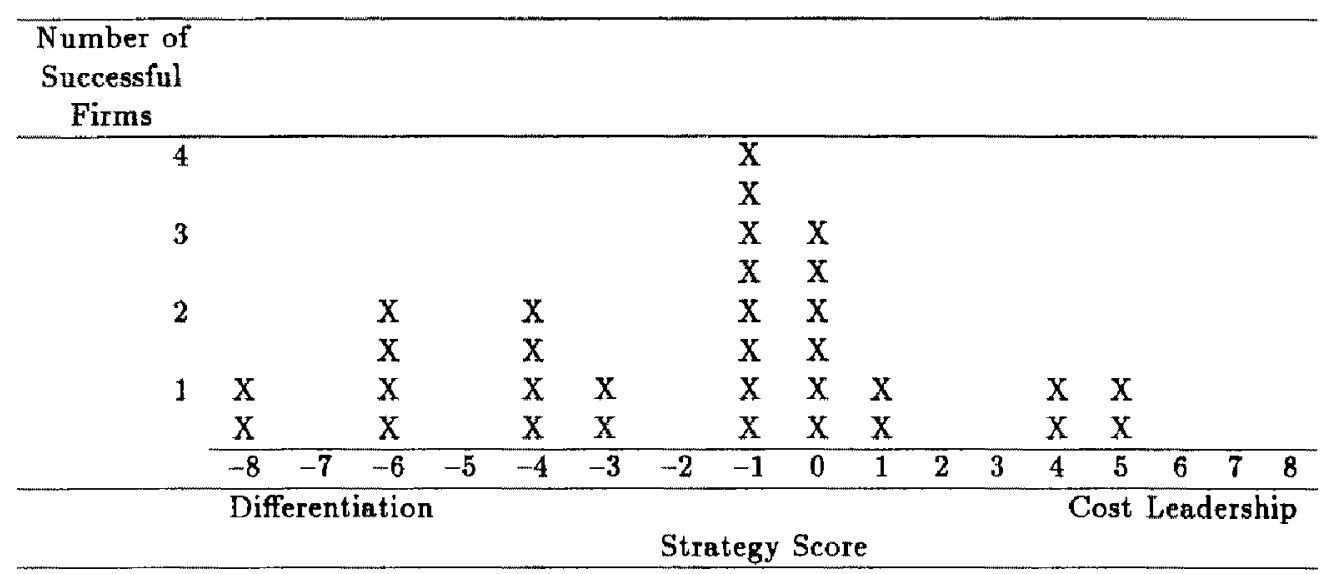

Table 2

Cross Tabulation by Performance and Strategy

Performance

\begin{tabular}{|c|c|c|c|}
\hline $\begin{array}{l}\text { High } \\
(16)\end{array}$ & $\begin{array}{ll} & \\
& \end{array}$ & B & $\bar{C}$ \\
\hline $\begin{array}{l}\text { Medium } \\
\quad(20)\end{array}$ & $\begin{array}{ll}\mathrm{D} & \\
& (2)\end{array}$ & $\mathrm{E}$ & $\mathbf{F}$ \\
\hline $\begin{array}{l}\text { Low } \\
\text { (11) }\end{array}$ & $\begin{array}{ll}\mathrm{G} & \\
& \text { (1) }\end{array}$ & $\mathrm{H}$ & I \\
\hline & Different & Mixed & Cost Lead \\
\hline
\end{tabular}

(8)

(35)

(4)

While the sample size and related cell distributions do not meet cell size requirements necessary to perform Chi Square tests, the distribution of firms as previously illustrated allows for generalizations concerning strategic orientation and performance. Of the 11 Low Performance firms, 10 were classified as following a mixed strategy, consistent with Porter's contention that such firms are "stuck in the middle." Likewise, 11 of the 12 firms classified as following either differentiation or cost leadership strategies were found to be in the Medium or High Performance groups. Again, this is entirely consistent with the claims of Porter's typology. However, the distribution of firms in the High Performance group is of major concern. Nine of the 16 firms in this group were found to follow a mixed strategy. Likewise, 16 of the 20 firms in the Medium Performance group were those with the mixed strategy. This is in conflict 
with Porter's claim that the vast majority of all firms must follow a single generic strategy in order to insure profitability and success.

\section{Conclusions}

This study focuses on the use of discrete, mutually exclusive measures to describe a firm's strategic orientation. It was hypothesized that should Porter's typology prove valid, a continuous measure of strategy would show successful firms to cluster at the extremes of the continuum, with unsuccessful firms assuming some mid-range position. With limited generalizations, this study clearly indicates that unsuccessful firms have, for the most part, failed to follow a single generic strategy resulting in $S$ scores near zero. There is strong evidence, however, that many firms perform successfully while following some type of mixed strategy, failing to support the existence of the U-shaped curve of Figure 1.

This finding is of particular interest in light of Miles and Snow's [7] allowance for mid-ranged firms described as analyzers. Closer examination reveals that the analyzer resembles a reactor in dealing with the three problems of the firm, with the major distinction being differences in performance and planning. This interpretation proves helpful in describing the firms classified as following a mixed strategy. Those Low Performance firms with $S$ scores near zero might be best compared to the reactors of the Miles and Snow typology. This score represents the attempt to follow several strategic alternatives without a clear understanding of the need for strategic direction. This corresponds to Porter's description of "stuck in the middle." Those High Performance firms with similar $S$ scores might be compared to the analyzers of Miles and Snow, firms who follow a mid-ranged position by choice. Such firms are successful, not because they follow a single generic strategy, but because they follow a consistent mixed strategy, accepting the trade-off of lower quality, but with corresponding lower prices.

Further examination of these firms' relative emphasis on competitive methods provides additional insight into their orientation. For example, an $S$ score of zero indicates that relative emphasis on $D$ and $C L$ is equal, but does not describe the magnitude of the emphasis. A firm with $D$ and $C L$ scores of 20 , respectively, would generate the same $S$ score as one with $D$ and $C L$ of 12 , respectively. While both firms are "stuck in the middle" according to Porter (i.e., neither one dominates), there is a difference. The firm with the higher scores for $D$ and $C L$ attempts to emphasize both strategies equally, and to the fullest extent possible. The firm with the lower scores for $D$ and $C L$ attempts to emphasize the strategies equally, but realizes that a tradeoff exists due to the limited resources of the firm. Of the 10 Low Performance-mixed strategy firms, 5 indicated a high emphasis on both $D$ and $C L$, indicating that both strategies were highly emphasized with equal intensity. Of the 9 High Performancemixed strategy firms, only 2 indicate high relative emphasis on both $D$ and $C L$. It follows that firms pursuing a mixed strategy are more likely to attain successful levels of performance by acknowledging the trade-off of strategic emphasis attributable to limited resources. 
Porter's use of discrete, mutually exclusive groupings seems to lack the explanatory power of the Miles and Snow model. The ability to explain the strategic reasoning of firms who follow mixed strategies seems to be a useful tool for those who use typologies to establish strategic group membership. The use of a continuum such as the one proposed allows for classification of firms by type without disqualifying mid-ranged firms who follow clearly defined mixed strategies. Validation of this (or a similar) strategy scoring system in a variety of business settings would yield significant insight into the actual application of Porter's typology.

\section{References}

1. Dess, Gregory G., and Davis, Peter S. "Porter's (1980) Generic Strategies as Determinants of Strategic Group Membership and Organizational Performance," Academy of Management Journal, Vol. 27, No. 3 (1984), pp. 467-88.

2. Green, Ronald F. "Competitive Bidding Processes: An Empirical Investigation of Strategic Orientation and Performance," unpublished dissertation, Clemson University (1986).

3. Hambrick, Donald C. "High Profit Strategies in Mature Capital Goods Industries: A Contingency Approach," Academy of Management Journal, Vol. 26, No. 4 (1983), pp. 687-707.

4. Hambrick, Donald C. and Lei, D. "Towards an Empirical Prioritization of Contingency Variables for Business Strategy," Academy of Management Journal, Vol. 28, No. 4 (1985), pp. 763-88.

5. Hill, Charles W. L. "Differentiation Versus Low Cost or Differentiation and Low Cost: A Contingency Framework," Academy of Management Review, Vol. 13, No. 3 (1988), pp. 401-12.

6. Karnani, A. "Generic Competition Strategies-An Analytical Approach," Strategic Management Journal, Vol. 5 (1984), pp. 367-80.

7. Miles, R. E., and Snow, C. C. Organizational Strategy, Structure and Process. New York: McGraw-Hill (1978).

8. Murray, Alan I. "A Contingency View of Porter's Generic Strategies," Academy of Management Review, Vol. 13, No. 3 (1988), pp. 390-400.

9. Parks, D. M. "An Empirical Examination of the Relationship Between the Strategic Typologies Proposed by Miles and Snow, Porter, and Hall," Proceedings of the Southern Management Association, Orlando, FL (November, 1985).

10. Phillips, L. W., Chang, D. R., and Buzzell, R. D. "Product Quality, Cost Position and Business Performance: A Test of Some Key Hypotheses," Journal of Marketing, Vol. 47, No. 2 (1983), pp. 26-43.

11. Porter, M. E. Competitive Strategy. New York: Free Press (1980).

12. Porter, M. E. Competitive Advantage. New York: Free Press (1985). 